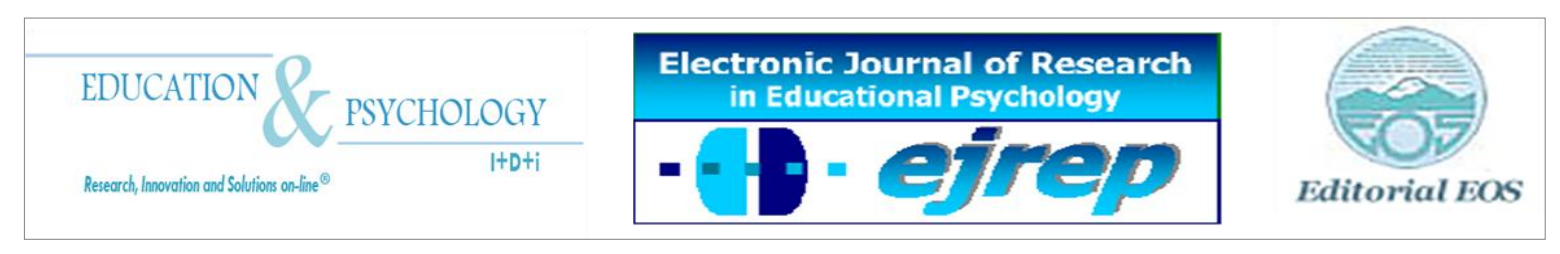

\title{
Methodological Constraints for Detecting the Modality Effect
}

\author{
Cornelia Schoor $^{1}$, Maria Bannert ${ }^{2}$, Verena Jahn ${ }^{3}$ \\ ${ }^{1}$ Psychology of Learning and Instruction, TU Dresden, Dresden \\ ${ }^{2}$ Educational Media, University of Würzburg, Würzburg \\ ${ }^{3}$ Educational Media, Chemnitz University of Technology, Chemnitz
}

\section{Germany}

Correspondence: Maria Bannert. Educational Media, Campus Hubland Nord, Theodor-Külpe-Weg, 82, 97070 Würzburg. Germany. E-mail: maria.bannert@uni-wuerzburg.de

(C) Education \& Psychology I+D+i and Editorial EOS (Spain) 


\begin{abstract}
Introduction. The aim of our research was to investigate the modality effect in more detail by measuring it in a direct way. Two studies were conducted using the same subject and material.

Method. Computer-based learning material was presented on several screens, each containing a short text and a picture. Modality was varied by presenting written versus oral text. Presentation time was system-paced and matched the time for oral text presentation. Based on the dual-task approach cognitive load was measured directly in terms of response time towards a stimulus. In study 1, we used a between-subjects design. Participants got the learning material (all screens) either presented visually (picture + written text, $\mathrm{N}=24$ ) or audiovisually in a combination of picture and oral text $(\mathrm{N}=24)$. In study 2 , we used the same learning material and cognitive load measurements as in study 1. However, instead of a between-subjects design, we varied text modality within participants $(\mathrm{N}=34)$ in such as that each participant received screens with text presented alternately in written and oral form. Starting modality was counterbalanced.
\end{abstract}

Results. In study 1, we found no modality effect with respect to response time and learning outcome whereas in study 2 , we found a significant difference in response times between screens with visually and orally presented text in the direction of the modality effect.

Conclusion. The results are discussed with regard to error variance in different experimental designs and effect size of the modality effect as well as with regard to capabilities of participants to strategically adjust to disadvantageous instructional conditions.

Keywords: multimedia learning, cognitive load, modality effect, dual task methodology

Received: 09/02/11 Initial acceptance: 09/15/10 Final acceptance: 11/14/11 


\section{Limitaciones metodológicas para detectar el efecto de la modalidad Resumen}

Introducción. El objetivo de nuestra investigación fue examinar al efecto de la modalidad más detallado por medio de la medición directa. Se realizaron dos estudios con el mismo tema y el mismo material.

Método. El material de aprendizaje asistido por ordenador fue presentado en varias páginas de la pantalla, cada una con un breve texto y una imagen. La modalidad fue variándose, presentando el texto de manera escrito frente a la oral. El tiempo de presentación fue el sistema de ritmo y juego con el tiempo para la presentación del texto oral. Basado en el enfoque de la doble tarea la carga cognitiva fue medido directamente en términos de tiempo de respuesta a un estímulo. En el estudio 1, se utilizó un diseño entre sujetos. Los participantes recibieron el material de aprendizaje (todas las páginas), o presentado visualmente (imagen y texto escrito, $\mathrm{N}=24$ ) o audiovisualmente (imagen y texto oral, $\mathrm{n}=24$ ). En el estudio 2 se utilizó el mismo material de aprendizaje y el mismo método de mensura de la carga cognitiva como en el estudio 1. Sin embargo, en lugar de un diseño entre sujetos, variamos la modalidad de texto dentro de los participantes $(\mathrm{N}=34)$ de modo que cada participante recibió las pantallas de texto presentado alternativo de manera escrita y oral. La modalidad de partida fue contrarrestada.

Resultados. En el estudio 1, no se encontraron efectos de modalidad con respecto al tiempo de respuesta y resultados de aprendizaje, mientras que en el estudio 2, se encontró una diferencia significativa en los tiempos de respuesta de una pantalla con el texto visual u oral en la dirección del efecto de la modalidad.

Conclusión. Los resultados se discuten en relación a la variación del error en los diferentes diseños experimentales y el tamaño del efecto del efecto de modalidad, así como con respecto a las capacidades de los participantes para ajustar de manera estratégica para las desventajosas condiciones de enseñanza.

Palabras clave: aprendizaje multimedia, la carga cognitiva, el efecto de la modalidad, la metodología de doble tarea.

Recibido: 02/09/11

Aceptación inicial: 15/09/11

Aceptación final: 14/11/11 


\section{Introduction}

Research on instructional designs that are most conducive to learning has been very extensive in recent years (e.g. Ayres \& Paas, 2009; Ayres \& Van Gog, 2009; Chen \& Chang, 2009; Verhoeven, Schnotz, \& Paas, 2009), particularly in the context of cognitive load theory (e.g. Chandler \& Sweller, 1991; Sweller, 1988) or multimedia learning theory (Mayer, 2001). In this context, cognitive load theory differentiates three kinds of cognitive load induced by learning material (Sweller, Van Merrienboer, \& Paas, 1998): Intrinsic cognitive load results from characteristics of the content, whereas inadequate instructional design leads to extraneous cognitive load. As a third source, germane cognitive load stems from processes of schema construction and automation. Too much load being impedimental, instructional design based on cognitive load theory tries to reduce cognitive load as much as possible, which preferably starts with decreasing extraneous cognitive load. Though being very neat, this conceptualization raises several theoretical and empirical questions (c.f. Schnotz \& Kürschner, 2007) so that more research is needed and evoked.

The modality effect (e.g. Low \& Sweller, 2005) refers to extraneous cognitive load: When presenting a graphic with explaining text, displaying the text in a visual form is disadvantageous compared to displaying the text auditorily. Mayer and Moreno (1998) explain this effect with two working memory subsystems being used in the auditory context (visual and auditory subsystem) whereas the visual-only format leaded to overloading of one subsystem (the visual subsystem). However, this explanation is questionable. First of all, it is not in line with Baddeley's working memory model according to which verbal information is processed by the auditory subsystem whether it is presented visually or auditorily (c.f. Baddeley, 2001). Second, an alternative explanation in terms of split attention (c.f. Chandler \& Sweller, 1992) gets more and more regard. The split attention effect says that integration of spatially or temporally distributed material provokes worse performance than learning with non-distributed material. With regard to the modality effect, visual text presentation can be seen as spatially distributed material (therefore leading to split attention) whereas in case of auditory text presentation, text and graphic can be processes simultaneously (c.f. Rummer, Schweppe, Scheiter, $\&$ Gerjets, 2008). The modality effect was also found in sequentially presented material (Moreno \& Mayer, 1999), but Rummer, Schweppe, Fürstenberg, Seufert, and Brünken (2010) were able to show that this effect might also not be due to better use of working memory ca- 
pacity but due to basic information processing mechanisms. Therefore, it is questionable whether the modality effect can be seen as an autonomous effect.

In order to study the modality effect (and other cognitive load effects) in its processes, it is essential to measure cognitive load as directly and objectively as possible. Brünken, Plass, and Leutner (2003) list different groups of cognitive load measurements: Among direct subjective and indirect subjective measurements they subsume subjective rating scales on invested mental effort or perceived difficulty. Physiological measures and learning outcome rank among indirect objective measures. Direct objective measures comprise for example dual task performance or brain activity measurements.

The dual task approach to measure cognitive load acts on the assumption that as cognitive resources (precisely: working memory capacity) are constraint one can measure cognitive load of a primary task by setting a secondary task. Performance on this secondary task shows how much working memory capacity is still left when fulfilling the primary task. Therefore, a consuming primary task should result in worse performance in the secondary task than a cognitively undemanding primary task. Accordingly, the better the performance in the secondary task the lower the cognitive load of the primary task. However, this effect depends on an appropriate design of the secondary task (c.f. Schoor, Bannert, \& Brünken, 2010).

\section{Objectives}

In our research, we used a direct objective measurement to further analyze the modality effect and the importance of the secondary task in dual task measurement of cognitive load. In two studies, we tried to replicate the modality effect. In study 1, we used a betweensubjects design; in study 2, we used a within-subjects design. Independently of the design, an auditory text presentation is expected to be advantageous in terms of reaction times on a (visual) secondary task compared to visual text presentation.

\section{Method of Study 1: Between-Subjects Design}

\section{Participants and design}

In this study, 48 university students took part. All of them were freshmen in educational science and participated in exchange for course credit. 44 participants were female 
(91.7\%) and 4 were male (8.3\%) which is quite representative for this program of study. Their mean age was $20.6(\mathrm{SD}=3.48)$.

We realized a one-factorial design with the between-subjects factor 'modality of information presentation'. Participants were randomly assigned to one of the two conditions resulting in $\mathrm{N}=24$ for the audiovisual condition and $\mathrm{N}=24$ for the visual-only condition.

\section{Procedure}

Participants were tested individually in groups of up to 8 at one time in our multimedia laboratory. A trained experimenter welcomed them and randomly placed them in front of one of the computers (Pentium 4 with 17 inch monitor, 1024 x 768 pixels, and Windows XP operating system). Participants first had to fill in a paper-based questionnaire covering control variables like demographics and computer usage, and then took a prior knowledge test. After that, participants learned how to fulfill the secondary task at the computer and baseline measurements were taken. Then participants started working with the learning material at the computer. During this, they had to fulfill their secondary task. After learning, they filled in a paper-based knowledge test on their learning outcome and were dismissed.

\section{Measures}

Prior knowledge test. The prior knowledge test was developed and has previously been used by Brünken, Steinbacher, Plass, and Leutner (2002) and Brünken and Leutner (2001). It comprised of 15 multiple choice questions with four answer alternatives each of which could be right or wrong covering knowledge presented in the learning material, as well as an option "I don't know." The knowledge test was delivered in a paper-pencil based format.

Knowledge test (learning outcome). All knowledge tests concerning the learning outcome were developed and have previously been used by Brünken et al. (2002) and Brünken and Leutner (2001). The knowledge test consisted of 15 multiple choice declarative knowledge questions different from the prior knowledge test merged with 18 picture recognition items as well as of an additional transfer multiple choice test. The declarative knowledge multiple choice items had four answer alternatives each of which could be right or wrong covering knowledge presented in the learning material. The picture recognition items required the correct labels to be filled in. The transfer multiple choice test with 10 items required the par- 
ticipants to draw correct conclusions from what they had learned. For each item, one out of 24 answer alternatives was correct. All tests were delivered in a paper-pencil-based form.

Primary task. Learning material. Learning material was the same computer based training (CBT) program used by Brünken et al. (2002). However, we rebuilt it in Eprime version 1.1 in order to integrate the secondary task into one and the same program. The CBT program comprised of 22 screens with text and a related picture covering the human cardiovascular system. The text was delivered either in a written (visual-only modality) or oral (audiovisual modality) form depending from the participant's condition (between-subjects factor 'modality of information presentation'). Presentation time was system-paced for both modalities of information presentation. The duration of presentation was as long as it took the speaker in the audiovisual modality of information presentation to read out the text. The CBT program overall took 13 minutes 14 seconds.

Secondary task and baseline measurements. As secondary task we used the same experimental setup as Brünken et al. (2002): In the middle of the upper part of the screen a black letter in a box was presented $(2.81 \mathrm{~cm} \mathrm{x} 3 \mathrm{~cm}$, c.f. figure 1). After a random period of 5 to 8 seconds, the letter color changed from black to red. In this case, participants had to press the space bar on the keyboard as soon as possible. Eprime recorded the time lapse between the color change and the pressing of the space bar. After pressing, the letter color changed back to black. If participants did not react within 5 seconds, time lapse was set to 5 seconds and the letter color was automatically set back to black.

Baseline measurements of the secondary task were taken for both groups: In a first block, participants had to fulfill the secondary task on an otherwise empty screen (60 seconds). In a second block (60 seconds), participants got the secondary task on a screen designed according to their modality: In visual-only modality, they received a written dummy text (Lorem ipsum) with a dummy picture on the screen (picture of a fir tree) while in the audiovisual condition, they received the same dummy picture but only the heading of the dummy text as it would be the screen design for the audiovisual learning material. 


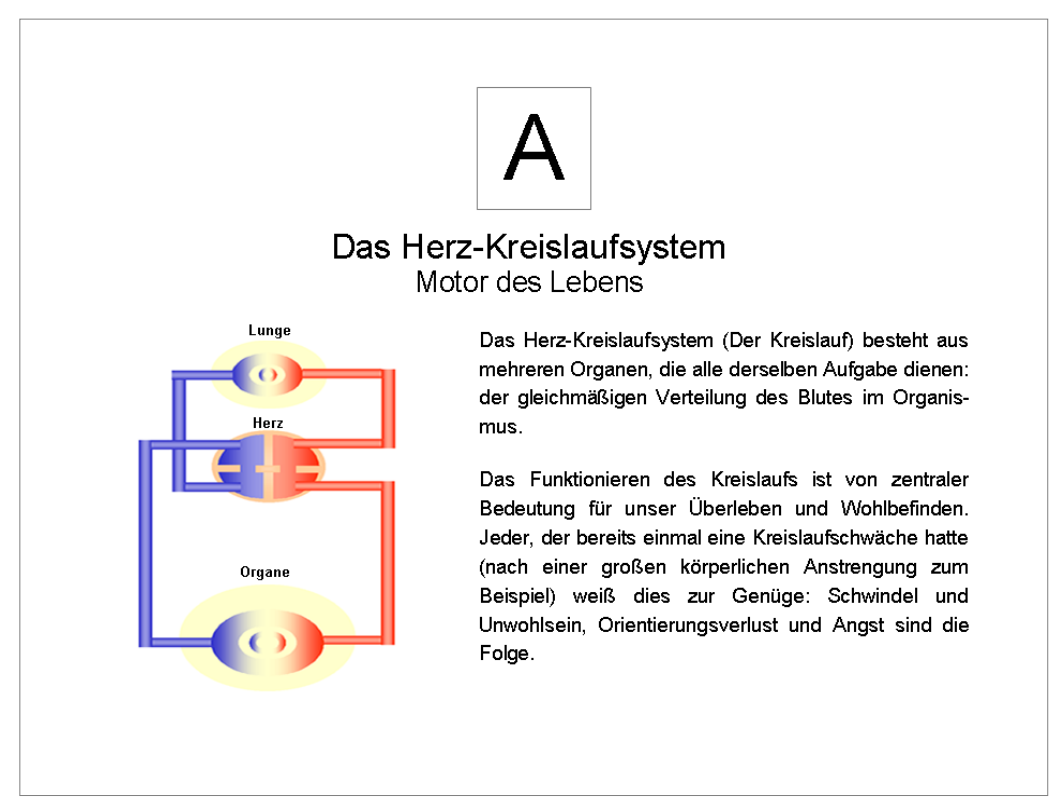

Figure 1. Sample screen of the learning material with secondary task (monitoring letter color of the ' $A$ ') in the upper part of the screen.

As the participants had to get used to their task, we did not use the first value of each baseline. Due to the random period of color change, the number of changes (and therefore the number of reaction time values obtained) varied for each participant. As training effects are possible, we used only six reaction time values for building a mean baseline value for all participants (values 2-7 for each kind of baseline).

\section{Results of Study 1}

There were no a priori differences in knowledge prior to learning (c.f. table 2) or in reaction times baseline measures (c.f. table 1) between the two groups. According to the modality effect, participants with audio-visual information presentation should show shorter reaction times on the secondary task during learning as well as a higher knowledge in the posttests.

\section{Modality effect in reaction times during learning}

As table 1 shows, there were no group differences in reaction times during learning. Including baseline $1\left(F(2,45)=1.98, p>.15, \eta_{\mathrm{p}}{ }^{2}=.08\right)$, baseline $2(F(2,45)=1.10, p>.33$, $\left.\eta_{\mathrm{p}}{ }^{2}=.05\right)$ or both $\left(F(3,44)=1.30, p>.28, \eta_{\mathrm{p}}{ }^{2}=.08\right)$ as covariates did not change this result. Therefore, we could not detect the modality effect in terms of reaction times on the secondary task. 
Table 1. Reaction times (RT) in both experimental groups in study 1.

\begin{tabular}{lllllll}
\hline & $\begin{array}{c}\text { Audiovisual } \\
\text { modality } \\
(\boldsymbol{N = 2 4 )}\end{array}$ & $\begin{array}{c}\text { Visual-only } \\
\text { modality } \\
(\boldsymbol{N}=\mathbf{2 4})\end{array}$ & $\mathbf{F}$ & $\mathbf{d f}$ & $\mathbf{p}$ & $\boldsymbol{\eta}_{\mathbf{p}}{ }^{2}$ \\
\hline Baseline 1 & $338.60(75.71)$ & $333.79(62.76)$ & 0.06 & 1,46 & .81 & .00 \\
Baseline 2 & $384.67(132,89)$ & $466.88(193.97)$ & 2.93 & 1,46 & .09 & .06 \\
RT during learning & $782.69(350.79)$ & $878.31(354.43)$ & 0.88 & 1,46 & .35 & .02 \\
\hline
\end{tabular}

Modality effect in knowledge acquisition

As table 2 depicts, we found only a significant difference in knowledge after learning in the declarative knowledge test. However, the group with visual-only information presentation performed better. Therefore, we were not able to detect the modality in knowledge acquisition either.

Table 2. Knowledge scores in both experimental groups in study 1.

\begin{tabular}{|c|c|c|c|c|c|c|c|}
\hline & $\begin{array}{l}\text { Max. } \\
\text { points }\end{array}$ & $\begin{array}{c}\text { Audiovisual } \\
\text { modality } \\
(N=24)\end{array}$ & $\begin{array}{c}\text { Visual-only } \\
\text { modality } \\
(N=24) \\
\end{array}$ & $\mathbf{F}$ & df & $\mathbf{p}$ & $\eta_{p}^{2}$ \\
\hline Prior knowledge test & 60 & $7.33(6.23)$ & $7.83(6.13)$ & 0.08 & 1,46 & .78 & .00 \\
\hline Declarative knowledge & 60 & $20.46(8.88)$ & $26.17(7.50)$ & 5.79 & 1,46 & .02 & .11 \\
\hline Picture recognition test & 73 & $32.00(18.87)$ & $28.13(16.62)$ & 0.57 & 1,46 & .45 & .01 \\
\hline Transfer test & 33 & $11.96(7.36)$ & $13.92(10.20)$ & 0.66 & 1,45 & .42 & .01 \\
\hline
\end{tabular}

\section{Method of Study 2: Within-Subjects Design}

In study 2 , we realized the same experimental setting as in study 1 but in terms of a within-subjects design.

\section{Participants and design}

34 university students of educational science (79.4\% freshmen, 20.6\% sophomores) participated in the study. $76.5 \%$ of them were female, $23.5 \%$ were male. They were 21.8 years $(\mathrm{SD}=2.94)$ of age

We realized a one-factorial within-subjects design with the factor 'modality of information presentation'. Learning material was presented alternately in an audiovisual or visualonly format. Starting modality was counterbalanced. 


\section{Procedure}

The procedure was about the same as in study 1: After a pretest on demographics, control variables and the prior knowledge test, participants learned how to fulfill the secondary task and took baseline measurements of this. Then, participants worked with the learning material and had to fulfill the secondary task. After learning, they filled in the knowledge posttest and were dismissed.

\section{Measures}

Knowledge tests (prior knowledge and learning outcome). As prior knowledge test, we used in this study the declarative knowledge multiple choice posttest of study 1 but with the additional answer option 'I don't know'. As learning outcome test, this test was used again but without additional answer option.

Primary task: Learning material. Learning material was exactly the same as in study 1. However, this time, participants received the screens alternately in the visual-only and the audiovisual modality (within-subjects factor). Starting modality was counterbalanced.

Secondary task and baseline measurements. The secondary task was also identical to the one in study 1 . This time, baseline measures were taken in three different ways for each participant. Participants had in a first block to fulfill the secondary task on an otherwise empty screen (60 seconds). In a second block (40 seconds), participants had to fulfill their secondary task with a dummy picture on the screen (picture of a fir tree) and the dummy heading (Lorem ipsum) while listening to dummy text in another language the participants were not familiar with. In the last block (40 seconds), participants got their secondary task on a screen with the dummy picture and a written dummy text (Lorem ipsum).

\section{Results of Study 2}

\section{Knowledge acquisition}

As a within-subjects design was realized, knowledge acquisition only shows whether the participants took the primary task (learn the material) seriously (c.f. Brünken et al., 2002; Schoor et al., 2010). As every participant got the material both visually and audiovisually, the modality effect cannot emerge between participants. Table 3 shows descriptive values of the 
knowledge pre and post tests. A repeated measurement ANOVA revealed that the repeated measurement factor (i.e. the knowledge acquisition) was significant $(F(1,33)=27.74, p<$ $\left..001, \eta_{\mathrm{p}}{ }^{2}=.46\right)$. Therefore, we can conclude that the participants fulfilled their primary task of learning.

Table 3. Knowledge scores in study 2.

\begin{tabular}{lcrr}
\hline & $\begin{array}{c}\text { Max. } \\
\text { points }\end{array}$ & \multicolumn{1}{c}{ M } & (SD) \\
\hline Prior knowledge test & 60 & 8.65 & $(4.69)$ \\
Post knowledge test & 60 & 14.65 & $(5.61)$ \\
\hline
\end{tabular}

\section{Modality effect in reaction times during learning}

Two reaction times values were computed for each participant: one for visual-only information presentation format and one for audiovisual information presentation format. Outliers $(N=4)$ were excluded. Descriptive statistics are depicted in table 4. A repeated measurement ANOVA showed a significant modality effect $\left(F(1,29)=4.87, p<.05, \eta_{\mathrm{p}}{ }^{2}=.14\right)$

Table 4. Reaction times (in ms) in study $2(N=30)$.

\begin{tabular}{lcc}
\hline & M & (SD) \\
\hline Visual-only information presentation & 800.06 & $(243.56)$ \\
Audiovisual information presentation & 685.25 & $(216.51)$ \\
\hline
\end{tabular}

\section{General Discussion}

Interestingly, we were able to replicate the modality effect by means of a withinsubjects design (study 2) but not by means of a between-subjects design (study 1). We consider different explanations for these results possible: one statistical referring to error variance and effect size, and one referring to strategic capabilities of learners.

The statistical explanation for diverging results in a between-subjects design and a within-subjects design refers to characteristics of the used statistical methods. In ANOVA as used in a between-subjects design, results are significant if the quotient of treatment variance by error variance ( $\mathrm{F}$ value) reaches a threshold height. In repeated measurement ANOVA as used in a within-subjects design, the interesting quotient is treatment variance divided by error variance which is adjusted by between-person variance. This means that in our between- 
subjects study error variance was higher than in our within-subjects study as in the latter case, individual differences in reaction times were statistically purged by the method. Considering that these individual differences seem to make the difference between significant and nonsignificant results, our found modality effect seems to be of small effect size compared to individual differences.

Another explanation of our results refers to strategic capabilities of learners (c.f. Bannert, 2002; Sanchez, 2004). In our within-subjects design (study 2), modality of information presentation changed after each screen page. Therefore, participants in this study had to constantly switch their handling of the material. In contrast, in the between-subjects design (study 1), every participant got the learning material in the same modality for all content. Therefore, they got the opportunity to adjust to their learning situation respectively their specific information presentation modality. Maybe they developed strategies how to cope with the material, also with disadvantageous material (visual-only condition with a higher extraneous load). Analyzing the sequence of reaction times indicated shorter reaction times at the end of learning compared to the beginning which may support our interpretation: The modality effect might be only relevant for short learning material where learners cannot develop strategies to handle poor instructional design. Studies finding the modality effect (e.g. Mayer \& Moreno, 1998; Moreno \& Mayer, 1999; Tindall-Ford, Chandler, \& Sweller, 1997) often use (very) short learning material.

To sum up: Having found the modality effect only by means of a within-subjects design and not by means of a between-subjects design, we conclude that the modality effect might be a small effect compared to person variance in reaction times and that learners are able to (and do so!) strategically adjust to disadvantageous learning material. Both are methodological constraints for finding the modality effect: First, a between-subjects design might be disadvantageous for finding the modality effect due to the higher error variance compared to a within-subjects design. Second, a between-subjects design might give learners the opportunity to adjust to their condition so that poor instructional design as it is theoretically the case in the visual-only condition might not hinder learning and performance in a secondary task.

Assumed the modality effect is a small one and assumed learners can adapt to difficult learning situations we question whether it is worth to investigate conditions under which the modality effect occurs. Instead, we suggest to use further resources in multimedia research by 
taking a closer look at the abilities of learners and how to support them to cope with all kinds of learning material.

\section{References}

Ayres, P., \& Paas, F. (2009). Interdisciplinary perspectives inspiring a new generation of cognitive load research [Special issue]. Educational Psychology Review, 21(1). Special Issue.

Ayres, P., \& Van Gog, T. (2009). State of the art research into cognitive load theory [Special issue]. Computers in Human Behavior, 25(2). Special Issue.

Baddeley, A. (2001). Is working memory still working? American Psychologist, 56(11), 851864.

Bannert, M. (2002). Managing cognitive load. Recent trends in cognitive load theory. Learning and Instruction, 12, 139-146.

Brünken, R., \& Leutner, D. (2001). Aufmerksamkeitsverteilung oder Aufmerksamkeitsfokussierung? Empirische Ergebnisse zur „Split-AttentionHypothese“ beim Lernen mit Multimedia [Attention splitting or attention focussing? Empirical results concerning the „split-attention hypothesis“ in learning with multimedia]. Unterrichtswissenschaft, 29(4), 357-366.

Brünken, R., Plass, J., \& Leutner, D. (2003). Direct measurement of cognitive load in multimedia learning. Educational Psychologist, 38(1), 53-61.

Brünken, R., Steinbacher, S., Plass, J., \& Leutner, D. (2002). Assessment of cognitive load in multimedia learning using dual-task methodology. Experimental Psychology, 49(2), 109-119.

Chandler, P., \& Sweller, J. (1991). Cognitive load theory and the format of instruction. Cognition and Instruction, 8(4), 293-332.

Chandler, P., \& Sweller, J. (1992). The split-attention effect as a factor in the design of instruction. British Journal of Educational Psychology, 62, 233-246.

Chen, I-J., \& Chang, C.-C. (2009). Cognitive load theory: An empirical study of anxiety and task performance in language learning. Electronic Journal of Research in Educational Psychology, 7(2), 729-746.

Low, R., \& Sweller, J. (2005). The modality principle in multimedia learning. In R. Mayer (Ed.), The Cambridge Handbook of Multimedia Learning (pp. 147-158). New York: Cambridge University Press.

Mayer, R. E. (2001). Multimedia Learning. New York: Cambridge University Press. 
Mayer, R. E., \& Moreno, R. (1998). A split-attention effect in multimedia learning: Evidence for dual processing systems in working memory. Journal of Educational Psychology, 90(2), 312-320.

Moreno, R., \& Mayer, R. (1999). Cognitive principles of multimedia learning: The role of modality and contiguity. Journal of Educational Psychology, 91(2), 358-368.

Rummer, R., Schweppe, J., Fürstenberg, A., Seufert, T., \& Brünken, R. (2010). What causes the modality effect in multimedia learning? Testing a specification of the modality assumption. Applied Cognitive Psychology, 24(2), 164-176.

Rummer, R., Schweppe, J., Scheiter, K., \& Gerjets, P. (2008). Lernen mit Multimedia: Die kognitiven Grundlagen des Modalitätseffekts [Multimedia learning and the cognitive basis of the modality effect]. Psychologische Rundschau, 59(2), 98-107.

Sanchez, J. M. R. (2004). Self-regulated learning procedure for university students: the meaningful text-reading strategy. Electronic Journal of Research in Educational Psychology, 2(1), 113-132.

Schnotz, W., \& Kürschner, C. (2007). A reconsideration of cognitive load theory. Educational Psychology Review, 19(4), 469-508.

Schoor, C., Bannert, M., \& Brünken, R. (2010). Role of dual task design when measuring cognitive load. Manuscript submitted for publication.

Sweller, J. (1988). Cognitive load during problem solving: Effects on learning. Cognitive Science, 12, 257-285.

Sweller, J., Van Merrienboer, J., \& Paas, F. (1998). Cognitive architecture and instructional design. Educational Psychology Review, 10, 251-296.

Tindall-Ford, S., Chandler, P., \& Sweller, J. (1997). When two sensory modes are better than one. Journal of Experimental Psychology: Applied, 3(4), 257-287.

Verhoeven, L., Schnotz, W., \& Paas, F. (2009). Cognitive load in interactive knowledge construction [Special issue]. Learning and Instruction, 19(5). Special Issue. 